\title{
Impact of breast surgery on survival of patients with stage IV breast cancer: a SEER population-based propensity score matching analysis
}

\author{
Yuxiang Lin ${ }^{\text {Equal first author, } 1}$, Kaiyan Huang ${ }^{\text {Equal first author, } 1}{ }^{\text {, Qiang Zeng }}{ }^{2}$, Jie Zhang ${ }^{\text {Corresp., } 1}$, Chuangui Song ${ }^{\text {Corresp. } 1}$ \\ ${ }^{1}$ Department of Breast Surgery, Fujian Medical University Union Hospital, Fuzhou, Fujian, China \\ 2 Department of Pathology, Fujian Medical University First Affiliated Hospital, Fuzhou, Fujian, China \\ Corresponding Authors: Jie Zhang, Chuangui Song \\ Email address: zjie1979@gmail.com, scgfjxh@outlook.com
}

Background: Breast surgery for stage IV breast cancer remains controversial. The aim of this study was to investigate the impact of breast surgery on survival of stage IV breast cancer patients based on the Surveillance, Epidemiology, and End Results (SEER) database from 2010 to 2015.

Methods: In total, 13,034 patients were selected and divided into surgery and non-surgery groups. Univariate and multivariable analyses were conducted to determine factors related to survival.

Propensity score matching method was utilized to achieve balanced covariates across different groups. One-to-one (1:1) PSM was conducted to construct a matched sample consisting of pairs of surgery and non-surgery subjects. Breast cancer-specific survival (BCSS) and overall survival (OS) of the two groups were assessed by Kaplan-Meier plots and Cox proportional hazard regression models. Stratified analysis according to different variables was also performed.

Results: Patients treated with breast surgery were more likely to be younger, smaller tumor size, more advanced nodal status, higher histology grade and higher proportion of bone-only metastasis. Those who received chemotherapy and radiotherapy also tended to be treated with surgery. After adjustment for potential confounders, breast surgery group exhibited a better survival both in BCSS (HR=0.557, 95\% $\mathrm{Cl}=0.523-0.594, p<0.001)$ and $\mathrm{OS}(\mathrm{HR}=0.571,95 \% \mathrm{Cl}=0.537-0.607, p<0.001)$. After propensity score matching, the surgery and non-surgery group consisted of 2,269 patients respectively. The median survival time was 43 months for the surgery group and 27 months for the non-surgery group. KaplanMeier curves indicated that breast surgery could clearly improve both the BCSS and OS for patients with stage IV breast cancer. On multivariate analysis, surgery group was associated with a better survival compared with the non-surgery group (BCSS: $\mathrm{HR}=0.542,95 \% \mathrm{Cl}=0.499-0.589, p<0.001 ; \mathrm{OS}$ : $\mathrm{HR}=0.555$, $95 \% \mathrm{Cl}=0.512-0.601, p<0.001)$. Furthermore, this survival advantage persisted in all subgroups irrespective of age, race, tumor size, nodal status, histology grade, molecular subtype, chemotherapy status, radiotherapy status or status of distant metastasis.

Conclusion: Our study provided additional evidence that patients with stage IV breast cancer could benefit from breast surgery and it might play a more important role in multimodality therapy. 
1 Impact of breast surgery on survival of patients with stage IV breast cancer: a SEER population-based propensity score matching analysis

5 Yuxiang Lin ${ }^{1}$, Kaiyan Huang ${ }^{1}$, Qiang Zeng ${ }^{2}$, Jie Zhang ${ }^{1 *}$ and Chuangui Song ${ }^{1 *}$

$6{ }^{1}$ Department of Breast Surgery, Fujian Medical University Union Hospital, Fuzhou, Fujian, 7 China

$8 \quad 2$ Department of Pathology, Fujian Medical University First Affiliated Hospital, Fuzhou, Fujian, 9 China

11 Yuxiang Lin and Kaiyan Huang contributed equally to this work.

$13 *$ The corresponding author:

14 Jie Zhang, $\mathrm{PhD}$

15 Chuangui Song, PhD

16 Department of Breast Surgery, Fujian Medical University Union Hospital

17 No.29, Xin Quan Road, Gulou District, Fuzhou, Fujian Province, 350001, China

18 Phone: +8613960709993

$19 \quad$ Fax : $+8659183357896-8014$

20 E-mail: zjie1979@gmail.com (ZJ) or scgfjxh@outlook.com (SC) 


\section{Abstract}

Background: Breast surgery for stage IV breast cancer remains controversial. The aim of this study was to investigate the impact of breast surgery on survival of stage IV breast cancer patients based on the Surveillance, Epidemiology, and End Results (SEER) database from 2010 to 2015 .

Methods: In total, 13,034 patients were selected and divided into surgery and non-surgery groups. Univariate and multivariable analyses were conducted to determine factors related to survival. Propensity score matching method was utilized to achieve balanced covariates across different groups. One-to-one (1:1) PSM was conducted to construct a matched sample consisting of pairs of surgery and non-surgery subjects. Breast cancer-specific survival (BCSS) and overall survival (OS) of the two groups were assessed by Kaplan-Meier plots and Cox proportional hazard regression models. Stratified analysis according to different variables was also performed.

Results: Patients treated with breast surgery were more likely to be younger, smaller tumor size, more advanced nodal status, higher histology grade and higher proportion of bone-only metastasis. Those who received chemotherapy and radiotherapy also tended to be treated with surgery. After adjustment for potential confounders, breast surgery group exhibited a better survival both in BCSS $(\mathrm{HR}=0.557,95 \% \mathrm{CI}=0.523-0.594, p<0.001)$ and $\mathrm{OS}(\mathrm{HR}=0.571,95 \%$ $\mathrm{CI}=0.537-0.607, p<0.001)$. After propensity score matching, the surgery and non-surgery group consisted of 2,269 patients respectively. The median survival time was 43 months for the surgery group and 27 months for the non-surgery group. Kaplan-Meier curves indicated that breast surgery could clearly improve both the BCSS and OS for patients with stage IV breast cancer. On multivariate analysis, surgery group was associated with a better survival compared with the non-surgery group (BCSS: $\mathrm{HR}=0.542,95 \% \mathrm{CI}=0.499-0.589, p<0.001 ; \mathrm{OS}$ : $\mathrm{HR}=0.555,95 \%$ 
$44 \mathrm{CI}=0.512-0.601, p<0.001)$. Furthermore, this survival advantage persisted in all subgroups irrespective of age, race, tumor size, nodal status, histology grade, molecular subtype, chemotherapy status, radiotherapy status or status of distant metastasis.

Conclusion: Our study provided additional evidence that patients with stage IV breast cancer could benefit from breast surgery and it might play a more important role in multimodality therapy.

Keywords: Stage IV breast cancer; Prognosis; Surgical treatment; Stratified analysis

\section{Introduction}

Stage IV breast cancer (BC) refers to the tumor which has disseminated to distant sites. It is estimated that $3-25 \%$ of female breast cancer patients might have metastatic disease at presentation [1-4].

The main purpose of treatment for de novo stage IV breast cancer is to alleviate symptoms, improve the quality of life and prolong survival [5]. Advances in systemic treatment have greatly improved the control of metastatic disease and prolonged survival $[6,7]$. Therefore, the utility of breast surgery has become a question worth discussing. Several retrospective studies have demonstrated that local surgery was associated with a better survival in women with metastatic breast cancer [8-11] or in specific subgroups [12]. However, results from three prospective randomized trials have revealed discordant results with conflicting data [13-15]. In addition, it is noted that the act of surgery might accelerate metastatic growth and have an adverse effect on 
65 survival [16-18]. Therefore, most guidelines still recommend surgical intervention in palliative

66 situations or selected patients after response to initial systemic therapy.

67 To date, the role of surgery for de novo stage IV breast cancer patients is still ambiguous 68 and no consensus exists. Accordingly, we conducted this propensity score matching analysis to 69 investigate the impact of breast surgery on survival of stage IV breast cancer patients with data from a large population-based database (the Surveillance, Epidemiology, and End Results, SEER)

71 collected from 2010 to 2015.

\section{Material and methods}

73

\section{Study Patients}

We performed a retrospective study of women with an initial diagnosis of stage IV breast cancer who were recorded in the SEER*Stat version 8.3.4 database from 2010 to 2015 to ensure complete data and adequate follow-up duration. SEER database collects and publishes cancer incidence and survival data from population-based cancer registries covering about $30 \%$ of the population of the United States. According to the SEER program, the initial de novo IV stage breast cancer is defined if metastases are diagnosed in the first four months after the diagnosis. In our study, we analyzed age, race, histological grade, tumor size, nodal status, breast subtype, surgery status, type of surgery, chemotherapy status, radiation status and status of distant metastasis.

All subjects who received surgical treatment related to the primary tumor (masctomy or breast conserving surgery) were included in the surgery group. Patients who did not receive any resection of their primary tumor were categorized as not having surgery. The SEER database only provided information on radiotherapy administration (postoperative external beam 
87 radiotherapy or no radiotherapy/unknown), while it did not specify the site of radiotherapy.

88 Therefore, the site of the surgery was the primary site (breast) and the site of the radiotherapy

89 after the surgery could be the primary site and/or metastatic sites (such as bone). Information

90 about the chemotherapy status was defined as "Yes" or "No/Unknown", while the regimen of

91 chemotherapy was not supplied. In addition, the data about the anti-HER2 targeted therapy and

92 endocrine therapy was also not specified.

The SEER database offered only the first course treatment information at the time of

94 diagnosis and did not provide treatment information after relapse or progression. Therefore, all

95 treatments in this study were the first course treatment after being diagnosed with stage IV breast

96 cancer. In order to assess the effect of status of distant metastasis on survival, we divided those

97 patients into bone-only metastasis group and visceral metastasis group, the bone-only metastasis

98 group was defined according to the site of metastasis (bone metastasis: "Yes"; brain, liver or

99 lung metastasis: "No").

\section{Statistical analysis}

101 Continuous variables were summarized as median (and range) and were transformed into

102 dichotomous variables at the median value. $P$-values for comparisons of different variables were

103 calculated by chi-squared $\left(\chi^{2}\right)$ test or Fisher's exact test. Among women diagnosed with stage IV

104 disease, we sought to compare the overall survival (OS) and breast cancer specific survival

105 (BCSS) between patients who did and did not receive surgical treatment for their primary tumor.

106 The median survival time was also calculated. Kaplan-Meier survival curves were generated to

107 compare differences in survival probabilities over time between the surgery and non-surgery

108 groups. Univariable and multivariable Cox regression models were used to describe the

109 associations between surgery and risk of death. To account for large sample size, we selected the 
110 variables with $p<0.05$ which were significantly associated with BCSS or OS in the univariable

111 analysis. One-to-one (1:1) PSM was conducted to construct a matched sample consisting of pairs

112 of surgery and non-surgery subjects by optimal matching algorithm. Variables that were

113 significantly different between the two groups were utilized to generate propensity scores.

114 Specifically, we also conducted a stratified analysis with respect to BCSS and OS by age, race,

115 tumor size, nodal status, grade, molecular subtype, chemotherapy status, radiotherapy status and

116 bone-only metastasis or no. Psmatch2 module was used to perform propensity score matching in

117 Stata version 13.0 (SAS Institute Inc., Cary, NC, USA). Other statistical analyses were 118 performed with Statistical Package for the Social Sciences (SPSS, version 24.0) for Windows

119 (IBM, Chicago, IL, USA), with a two-sided $P$ value of less than 0.05 considered statistically 120 significant.

\section{Results}

\section{Clinicopathological characteristics of the selected patients}

In total, 13,034 patients with a diagnosis of stage IV breast cancer between 2010-2015 who

had complete information of breast surgery were included in this study. The patient selection

125 flow-chart was displayed in Figure 1. As shown in Table 1, 9,151 (70.2\%) patients did not

126 receive surgery and 3,883 $(29.8 \%)$ were treated with surgery. There were significant differences

127 between these two groups. Patients treated with breast surgery were more likely to be younger,

128 smaller tumor size, more advanced nodal status, higher histology grade and higher proportion of 129 bone-only metastasis. Furthermore, those who received chemotherapy and radiotherapy also 130 tended to be treated with surgery.

131 Comparison of survival between the surgery and non-surgery groups in all patients 
After the baseline characteristics were summarized, we used the Cox proportional hazards

133 model to investigate the effect of baseline characteristics on survival outcomes. A univariable

134

135

136

137

138

139

140

141

142

143

144

145

146

147

148

149

150

151

152 153

analysis indicated that older age, more advanced $\mathrm{T}$ or $\mathrm{N}$ stage, higher histology grades, triple negative breast cancer, visceral metastasis, an absence of chemotherapy or radiotherapy and patients without surgery were significantly associated with a worse BCSS and OS $(p<0.001)$ (Table S1). Furthermore, we included all variables mentioned earlier in the multivariable analysis. After adjustment for potential confounders, breast surgery was identified as an independent protective factor for both $\mathrm{BCSS}(\mathrm{HR}=0.557,95 \% \mathrm{CI}=0.523-0.594, p<0.001)$ and $\mathrm{OS}$ $(\mathrm{HR}=0.571,95 \% \mathrm{CI}=0.537-0.607, p<0.001)($ Table 2$)$.

\section{Survival analysis in matched groups}

To further evaluate the detected differences between breast surgery and non-surgery groups, we performed a 1:1 matched case-control analysis using the propensity score matching method. Propensity score matching between the surgery and non-surgery groups was conducted by all variables (age, race, $\mathrm{T}$ and $\mathrm{N}$ categories, histology, grade, molecular subtype, chemotherapy or radiation status, bone-only metastasis or not). After PSM, the surgery and non-surgery group consisted of 2,269 patients respectively. No statistical differences were observed between the two groups. Kaplan-Meier curves of the BCSS and OS in the surgery and non-surgery groups after PSM are presented in Figure 2. Breast surgery clearly improved both the BCSS and OS for patients with de novo stage IV breast cancer. The median survival time was 43 months for the surgery group with 27 months for the non-surgery group. Univariable and multivariate analysis using the Cox proportional hazards model was also performed, with the relevant results shown in Table S2 and Table 3. As expected, the surgery group was associated with a marked survival 
154 advantage compared with the non-surgery group (BCSS: $\mathrm{HR}=0.542,95 \% \mathrm{CI}=0.499-0.589$,

$155 p<0.001$; OS: $\mathrm{HR}=0.555,95 \% \mathrm{CI}=0.512-0.601, p<0.001)$.

\section{Stratified survival analysis}

157 Furthermore, we performed a stratified analysis according to different variables in 1:1

158

159

160

161

162

163

164

165

166

167

168

169

170

171

172

173

174

175

matched groups. The Kaplan-Meier survival function was used to generate Figure 3 and Figure 4 in the hierarchical analysis, which represent the overall survival between surgery and nonsurgery patients with different tumor size, nodal status, molecular subtypes and status of distant metastases. The median survival time for hormone receptor positive HER2 negative (HR+HER2-) and triple negative (TNBC) subtype was 47 months (surgery) vs. 32 months (non-surgery) and 16 months (surgery) vs. 11 months (non-surgery) respectively. While for bone-only metastasis and visceral metastasis patients, the median survival time was 52 months (surgery) vs. 36 months (non-surgery) and 36 months (surgery) vs. 22 months (non-surgery) respectively. Table 4 shows the hazards ratio (HR) and 95\% confidence interval (CI) of the surgery group, which was determined by Cox regression analysis contrasted with that of the non-surgery group. Breast surgery was indicated to significantly reduce mortality risk regardless of tumor size, nodal status, molecular subtype or status of distant metastasis. Similarly in other subgroups (Figure 5), surgery also presented a more favorable overall survival irrespective of age, race, histology grade chemotherapy status or radiotherapy status.

\section{Multivariate analysis for patients in the surgery group}

We also performed a multivariate analysis by Cox proportional hazards model for patients with breast surgery in 1:1 matched groups (Table 5). For both BCSS and OS, older age, more advanced $\mathrm{T}$ stage, higher histology grades, triple negative breast cancer, visceral metastasis and 
176 an absence of chemotherapy presented a worse prognosis. $\mathrm{N}$ stage and type of surgery

177 (masctomy or breast conserving surgery) remained irrelevant to the survival of this group of

178 patients. While radiotherapy was identified to be a significantly favorable factor both in BCSS

179 and $\mathrm{OS}(\mathrm{HR}=0.819,95 \% \mathrm{CI}=0.694-0.966, p=0.018 ; \mathrm{HR}=0.783,95 \% \mathrm{CI}=0.667-0.920, p=0.003)$.

180 Discussion

181 In this large population-based cohort study, we sought to reveal the distinct outcomes of 182 stage IV breast cancer with or without surgical intervention based on the SEER population-based 183 data. Our findings indicated that the surgery group was associated with a better survival compared with the non-surgery group $(\mathrm{BCSS}$ : $\mathrm{HR}=0.542,95 \% \mathrm{CI}=0.499-0.589, p<0.001$; OS: $\mathrm{HR}=0.555,95 \% \mathrm{CI}=0.512-0.601, p<0.001)$. Furthermore, this survival advantage persisted in all subgroups irrespective of age, race, tumor size, nodal status, histology grade, molecular subtype, chemotherapy status, radiotherapy status or status of distant metastasis.

Metastatic breast cancer is still considered as a systemic disease and local therapy would only have little impact on outcomes [19]. The primary aim of treatment is to alleviate symptoms, improve the quality of life and prolong survival. In clinical practice, the majority of patients with

191 de novo stage IV breast cancer are recommended to receive systemic therapy including chemotherapy, anti-HER2 therapy or endocrine therapy. Surgery is mainly considered when there is tumor bleeding or ulceration [20]. Earlier studies also suggested that the growth of distant metastases could be stimulated by removal of primary tumor. Surgical intervention could reduce angiostatin secretion and stimulate the release of growth factors, thus accelerating metastatic growth and presenting an adverse effect on survival [16-18, 21]. However, other experimental studies in the murine model indicated that substantially reducing overall tumor 
199 primary tumor's suppression of the immune response and its surgical removal could result in

200 restored immunocompetence [23].

201 Therefore, the utility of surgical intervention in this population has long been debated.

202 Multiple retrospective studies have revealed the potential benefit with surgery [8-12, 24-28]. The

203 most recent study based on the SEER database (1998-2011) proposed a survival advantage with

204 surgical intervention (median overall survival, 34 months for surgery vs. 18 months for non-

205 surgery) [29]. However, the data about HER2 status in this study were incomplete and no

206 stratified analysis was conducted. One study based on NCDB database also noted a benefit for

207 stage IV breast cancer patients with surgery [11]. In a large cohort of 11,694 patients, an

208 improved overall survival was observed for the surgery group compared with the non-surgery

209 group after propensity score matching $(\mathrm{HR}=0.68,95 \% \quad \mathrm{CI}=0.63-0.72, p<0.001)$. These

210 conclusions are similar to the results in our study, providing consistent evidence from registry-

211 based retrospective studies that well-selected patients with de novo stage IV breast cancer who

212 undergo surgical intervention could obtain a better survival.

213 In spite of the evidence in several retrospective studies, supportive prospective analyses still

214 lacked. Fitzal's study (ABCSG-28 POSYTIVE) enrolled 90 previously untreated stage IV breast

215 cancer patients and randomly assigned them to surgical resection followed by systemic therapy

216 group or primary systemic therapy group [13]. This trial was stopped early due to poor

217 recruitment and the median overall survival for surgery and non-surgery group was 34.6 and 54.8

218 months respectively $(\mathrm{HR}=0.691,95 \% \mathrm{CI}=0.358-1.333 ; p=0.267)$. MF07-01 trial [14] is another

219 prospective, multicenter, phase III, randomized trial to focus on the impact of breast surgery on

220 the survival of de novo stage IV BC patients. In this study, one group received sequential

221 systemic therapy after primary surgery and the other group only received systemic therapy alone. 
222 Local surgery did not gained a survival advantage after 3 years of follow-up. But after 5 years of

223 follow-up, patients with local surgery achieved a better overall survival $(\mathrm{HR}=0.66,95 \% \mathrm{CI}=$

$2240.49-0.88 ; p=0.005)$. Unplanned subgroup analyses indicated that the survival benefit of breast

225 surgery presented in patients with younger age ( $<55$ years), ER/PR positive, HER2 negative or

226 solitary bone-only metastases. Although these findings identified the therapeutic value of breast

227 surgery and suggested several factors such as molecular subtype or metastatic site that should be

228 taken into consideration, controversy still existed for the procedure of surgical resection followed

229 by systemic therapy did not accord with the clinical practice now. The other prospective trial by

230 Badwe et al. [15] randomly included 350 previously untreated de novo metastatic BC patients

231 from India between 2005 to 2013 . Median overall survival was 19.2 months (95\% CI=15.98-

232 22.46) in the surgery group and 20.5 months (16.96-23.98) in the non-surgery group $(\mathrm{HR}=1.04$,

$23395 \% \mathrm{CI}=0.81-1.34 ; p=0.79)$. The uncertain effect of surgery in this study might be attributed to

234 the fact that only few patients enrolled received paclitaxel-based chemotherapy and most of

235 HER2 positive patients did not take anti-HER2 therapy.

236 Our current study of the SEER database provided strong retrospective data of breast surgery

237 in stage IV breast cancer. It is expected that patients with lower disease burden and better

238 prognostic factors such as ER+HER- subtype or bone-only metastasis are more likely to

239 undertake surgery, thereby resulting a better prognosis. In a matched paired retrospective

240 analysis, it is noted that selection bias in stage IV breast cancer could affect the survival

241 outcomes[30]. Therefore, propensity score matching analysis was applied in our study to balance

242 covariates in different groups and reduce selection bias. The results of propensity score matching

243 indicated that surgical intervention obtained a significant survival benefit. Furthermore, patients

244 with surgery were shown to significantly reduce mortality risk in different subgroups, regardless 
245 of age, race, histology grade, tumor size, nodal status, molecular subtype, chemotherapy status or

246 status of distant metastasis, suggesting that breast surgery might have independent therapeutic

247 value to improve survival in stage IV breast cancer. However, one point that should be

248 mentioned is a relatively poor survival for stage IV triple negative breast cancer (TNBC) patients.

249 The median survival time for TNBC patients was 16 months (surgery) vs. 11 months (non-

250 surgery) respectively. Although surgical intervention revealed a better survival outcome, whether

251 these patients should received surgery required further discussion. For patients with breast

252 surgery, we also performed a multivariate analysis. Type of surgery (masctomy or breast

253 conserving surgery) remained irrelevant to the survival, while radiotherapy was identified to be a

254 significantly favorable factor both in BCSS and OS ( $\mathrm{HR}=0.819,95 \% \mathrm{CI}=0.694-0.966, p=0.018$;

$255 \quad \mathrm{HR}=0.783,95 \% \mathrm{CI}=0.667-0.920, p=0.003)$.

256 Stage IV breast cancer is a group of highly heterogeneous disease. Advances in systemic

257 treatment have greatly improved the control of metastases disease. Five-year disease special

258 survival of de novo breast cancer has been improved from 28\% (1990-1998) to 55\% (2005-2010)

259 [31]. Therefore, local treatment might play a more important role than conventionally considered

260 in metastatic breast cancer patients. However, several limitations should also be mentioned in

261 our study. Firstly, although propensity score matching analysis was utilized, selection bias

262 (regarding the retrospective design) and guarantee time bias (those who do not live long enough

263 to undergo surgery are classified to the no-surgery group) still existed. Secondly, information

264 about anti-HER2 targeted therapy and endocrine therapy is absent, while the regimen of

265 chemotherapy and the exact site of radiotherapy (primary tumor or metastasis site such as bone)

266 are also unavailable from the SEER database. Data on performance status and comorbidities are

267 also not presented for they are vital as these could be the factors that prevailed in surgery 
268 decision-making process. Thirdly, the status of disease burden is incomplete (SEER database

269 does not provide the number of metastases, but only with the information of the major sites, such

270 as bone, lung, liver, brain and distant lymph nodes). In addition, a possibility of late diagnosis of

271 metastatic disease could also impact the interpretation of the results (For in SEER database, the

272 initial de novo breast cancer is defined if metastases are diagnosed in the first four months after

273 the diagnosis). Lastly, we could not determine the timing of surgery for patients included,

274 whether the breast surgery was performed after systemic treatment or at initial diagnosis is also 275 unknown.

276 In conclusion, our study provided additional evidence that patients with stage IV breast 277 cancer could benefit from surgical treatment. Future multicenter, large-scale prospective studies 278 with long-term follow-up are still warranted.

\section{Acknowledgments}

This study was supported by grants from National Natural Science Foundation of China

281 (81672817), Joint Funds for the Innovation of Science and Technology, Fujian Province $282(2017 Y 9033)$.

\section{Disclosures}

284 The authors have declared that no competing interests exist.

\section{Compliance with Ethical Standards}

\section{$286 \quad$ Ethical approval} any of the authors. 


\section{Informed consent}

As this study contains data released by the SEER database which are publicly available and

291 de-identified, informed consent was not needed.

292

293

\section{Figure Captains}

294

Figure 1. Flow chart for the patient selection from SEER database.

Figure 2. Kaplan-Meier curves of breast cancer specific survival (A) and overall survival (B) in the surgery and non-surgery groups after propensity score matching.

Figure 3. Kaplan-Meier curves of overall survival in the surgery and non-surgery groups stratified by different tumor size and nodal status. (A) T1+T2, (B) T3+T4, (C) N0+N1, (D) $\mathrm{N} 2+\mathrm{N} 3$.

Figure 4. Kaplan-Meier curves of overall survival in the surgery and non-surgery groups stratified by molecular subtypes and status of distant metastasis. (A) HR+HER2-, (B) TNBC, (C) bone-only metastasis, (D) visceral metastasis.

Figure 5. Forest plot of overall survival in the surgery and non-surgery groups stratified by age, race, histology grade, chemotherapy status and radiotherapy status.

\section{References}

306 [1] Siegel RL, Miller KD, Jemal A. Cancer statistics, 2019. CA Cancer J Clin. 2019;69(1):7-34.

307 doi:10.3322/caac.21551.

308 [2] Miller JW, Smith JL, Ryerson AB, Tucker TC, Allemani C. Disparities in breast cancer 309 survival in the United States (2001-2009): Findings from the CONCORD-2 study. Cancer. 310 2017;123 Suppl 24:5100-18. doi:10.1002/cncr.30988. 
311 [3] Eng LG, Dawood S, Sopik V, Haaland B, Tan PS, Bhoo-Pathy N, Warner E, Iqbal J, Narod 312 SA, Dent R. Ten-year survival in women with primary stage IV breast cancer. Breast Cancer Res 313 Treat. 2016;160(1):145-52. doi:10.1007/s10549-016-3974-x.

314 [4] Unger-Saldaña K. Challenges to the early diagnosis and treatment of breast cancer in 315 developing countries. World J Clin Oncol. 2014;5(3):465-77.

316 [5] Sanchez-Munoz A, Perez-Ruiz E, Ribelles N, Marquez A, Alba E. Maintenance treatment in 317 metastatic breast cancer. Expert Rev Anticancer Ther. 2008;8(12):1907-12.

318 doi:10.1586/14737140.8.12.1907.

319 [6] Dawood S, Haaland B, Albaracin C, Gupta S, Cortes J, Sim YY, Dent RA. Is the proportion 320 of patients diagnosed with synchronous stage IV breast cancer who survive more than two years 321 increasing over time? Oncology. 2015;89:79-87.

322 [7] Corona SP, Sobhani N, Ianza A, Roviello G, Mustacchi G, Bortul M, Zanconati F, Generali D. Advances in systemic therapy for metastatic breast cancer: future perspectives. Med Oncol. 2017;34(7):119. doi:10.1007/s12032-017-0975-5.

[8] AlJohani B, AlMalik O, Anwar E, Tulbah A, Alshabanah M, AlSyaed A, Ajarim D, ALTweigeri T. Impact of Surgery on Survival in Stage IV Breast Cancer. Breast J. 2016;22(6):678-82. doi:10.1111/tbj.12662.

[9] Warschkow R, Güller U, Tarantino I, Cerny T, Schmied BM, Thuerlimann B, Joerger M. Improved Survival After Primary Tumor Surgery in Metastatic Breast Cancer: A Propensityadjusted, Population-based SEER Trend Analysis. Ann Surg. 2016;263(6):1188-98. doi:10.1097/SLA.0000000000001302. IV Breast Cancer in the United States, 1988-2011. JAMA Surg. 2016;151(5):424-31. doi:10.1001/jamasurg.2015.4539. breast cancer. Breast J. 2019;25(4):644-53. doi:10.1111/tbj.13296.

337 [12] Rashaan ZM, Bastiaannet E, Portielje JE, van de Water W, van der Velde S, Ernst MF, van 338 de Velde CJ, Liefers GJ. Surgery in metastatic breast cancer: patients with a favorable profile 339 seem to have the most benefit from surgery. Eur J Surg Oncol. 2012;38(1):52-6.

340 doi:10.1016/j.ejso.2011.10.004.

341 [13] Fitzal F, Bjelic-Radisic V, Knauer M, Steger G, Hubalek M, Balic M, Singer C, Bartsch R, 342 Schrenk P, Soelkner L, Greil R, Gnant M; ABCSG. Impact of Breast Surgery in Primary 343 Metastasized Breast Cancer: Outcomes of the Prospective Randomized Phase III ABCSG-28 
344 POSYTIVE Trial. Ann Surg. 2019 Jun;269(6):1163-1169. doi:

$34510.1097 /$ SLA.0000000000002771.

346 [14] Soran A, Ozmen V, Ozbas S, Karanlik H, Muslumanoglu M, Igci A, Canturk Z, Utkan Z, 347 Ozaslan C, Evrensel T, Uras C, Aksaz E, Soyder A, Ugurlu U, Col C, Cabioglu N, Bozkurt B, 348 Uzunkoy A, Koksal N, Gulluoglu BM, Unal B, Atalay C, Yıldırım E, Erdem E, Salimoglu S, 349 Sezer A, Koyuncu A, Gurleyik G, Alagol H, Ulufi N, Berberoglu U, Dulger M, Cengiz O, 350 Sezgin E, Johnson R. Randomized Trial Comparing Resection of Primary Tumor with No 351 Surgery in Stage IV Breast Cancer at Presentation: Protocol MF07-01. Ann Surg Oncol. 352 2018;25(11):3141-9. doi:10.1245/s10434-018-6494-6.

353 [15] Badwe R, Hawaldar R, Nair N, Kaushik R, Parmar V, Siddique S, Budrukkar A, Mittra I, 354 Gupta S. Locoregional treatment versus no treatment of the primary tumour in metastatic breast 355 cancer: an open-label randomised controlled trial. Lancet Oncol. 2015;16(13):1380-8.

356 doi:10.1016/S1470-2045(15)00135-7.

357 [16] Gunduz N, Fisher B, Saffer EA. Effect of surgical removal on the growth and kinetics of 358 residual tumor. Cancer Res. 1979;39(10):3861-5.

359 [17] Al-Sahaf O, Wang JH, Browne TJ, Cotter TG, Redmond HP. Surgical injury enhances the expression of genes that mediate breast cancer metastasis to the lung. Ann Surg. 2010;252(6):1037-43. doi:10.1097/SLA.0b013e3181efc635.

[18] Retsky M, Bonadonna G, Demicheli R, Folkman J, Hrushesky W, Valagussa P. Hypothesis: Induced angiogenesis after surgery in premenopausal node-positive breast cancer patients is a major underlying reason why adjuvant chemotherapy works particularly well for those patients. Breast Cancer Res. 2004;6(4):R372-4. doi:10.1186/bcr804.

[19] Lane WO, Thomas SM, Blitzblau RC, Plichta JK, Rosenberger LH, Fayanju OM, Hyslop T, Hwang ES, Greenup RA. Surgical resection of the primary tumor in women with de novo stage IVbreast cancer: contemporary practice patterns and survival analysis. Ann Surg. 2019;269 (3):537-44.

[20] Arnedos M, Vicier C, Loi S, Lefebvre C, Michiels S, Bonnefoi H, Andre F. Precision medicine for metastatic breast cancer--limitations and solutions. Nat Rev Clin Oncol. 2015;12(12):693-704. doi:10.1038/nrclinonc.2015.123.

[21] Folkman J. New perspectives in clinical oncology from angiogenesis research. Eur J Cancer. 1996;32A(14):2534-9. doi:10.1016/s0959-8049(96)00423-6.

375 [22] Rashid OM, Nagahashi M, Ramachandran S, Graham L, Yamada A, Spiegel S, Bear HD, 376 Takabe K. Resection of the primary tumor improves survival in metastatic breast cancer by 377 reducing overall tumor burden. Surgery. 2013;153(6):771-8. doi:10.1016/j.surg.2013.02.002. 
378 [23] Danna EA, Sinha P, Gilbert M, Clements VK, Pulaski BA, Ostrand-Rosenberg S. Surgical

379

380

381

382

383

384

385

386

387

388

389

390

391

392

393

394

395

396

397

398

399

400

401

402

403

404

405

406

407

408

409 removal of primary tumor reverses tumor-induced immunosuppression despite the presence of metastatic disease. Cancer Res. 2004;64(6):2205-11.

[24] Gnerlich J, Jeffe DB, Deshpande AD, Beers C, Zander C, Margenthaler JA. Surgical removal of the primary tumor increases overall survival in patients with metastatic breast cancer: analysis of the 1988-2003 SEER data. Ann Surg Oncol. 2007;14(8):2187-94.

doi:10.1245/s10434-007-9438-0.

[25] Quinn EM, Kealy R, O'Meara S, Whelan M, Ennis R, Malone C, McLaughlin R, Kerin MJ, Sweeney KJ. Is there a role for locoregional surgery in stage IV breast cancer? Breast.

2015;24(1):32-7. doi:10.1016/j.breast.2014.10.009.

[26] Leung AM, Vu HN, Nguyen KA, Thacker LR, Bear HD. Effects of surgical excision on survival of patients with stage IV breast cancer. J Surg Res. 2010;161(1):83-8.

doi:10.1016/j.jss.2008.12.030.

[27] Blanchard DK, Shetty PB, Hilsenbeck SG, Elledge RM. Association of surgery with improved survival in stage IV breast cancer patients. Ann Surg. 2008;247(5):732-8. doi:10.1097/SLA.0b013e3181656d32.

[28] Eng LG, Dawood S, Sopik V, Haaland B, Tan PS, Bhoo-Pathy N, Warner E, Iqbal J, Narod SA, Dent R. Ten-year survival in women with primary stage IV breast cancer. Breast Cancer Res Treat. 2016;160(1):145-52. doi:10.1007/s10549-016-3974-X.

[29] Vohra NA, Brinkley J, Kachare S, Muzaffar M. Primary tumor resection in metastatic breast cancer: A propensity-matched analysis, 1988-2011 SEER data base. Breast J. 2018;24(4):549-54. doi:10.1111/tbj.13005.

[30] Cady B, Nathan NR, Michaelson JS, Golshan M, Smith BL. Matched pair analyses of stage IV breast cancer with or without resection of primary breast site. Ann Surg Oncol. 2008;15(12):3384-95. doi:10.1245/s 10434-008-0085-x.

[31] Malmgren JA, Mayer M, Atwood MK, Kaplan HG. Differential presentation and survival of de novo and recurrent metastatic breast cancer over time: 1990-2010. Breast Cancer Res Treat. 2018;167(2):579-90. doi:10.1007/s10549-017-4529-5. 


\section{Table 1 (on next page)}

Baseline Characteristics of stage IV patients with or without breast surgery before and after propensity score matching (PSM). 
1 Table 1: Baseline Characteristics of stage IV patients with or without breast surgery before and 2 after propensity score matching (PSM).

3

\begin{tabular}{|c|c|c|c|c|c|c|c|c|c|c|}
\hline \multirow{3}{*}{ Characteristics } & \multicolumn{4}{|c|}{ Before PSM } & \multirow{3}{*}{$P^{\mathrm{a}}$} & \multicolumn{4}{|c|}{ After PSM } & \multirow{3}{*}{$P^{\mathrm{a}}$} \\
\hline & \multicolumn{2}{|c|}{$\begin{array}{l}\text { Surgery } \\
(n=3883)\end{array}$} & \multicolumn{2}{|c|}{$\begin{array}{c}\text { Non-Surgery } \\
(n=9151)\end{array}$} & & \multicolumn{2}{|c|}{$\begin{array}{l}\text { Surgery } \\
(n=2269)\end{array}$} & \multicolumn{2}{|c|}{$\begin{array}{c}\text { Non-Surgery } \\
(\mathrm{n}=2269)\end{array}$} & \\
\hline & No & $\%$ & No & $\%$ & & No & $\%$ & No & $\%$ & \\
\hline \multicolumn{11}{|l|}{ Age (years) } \\
\hline 20-49 & 1163 & 30.0 & 1836 & 20.1 & $<0.001$ & 604 & 26.6 & 600 & 26.4 & 0.893 \\
\hline $50-79$ & 2720 & 70.0 & 7315 & 79.9 & & 1665 & 73.4 & 1669 & 73.6 & \\
\hline \multicolumn{11}{|l|}{ Race } \\
\hline White & 2841 & 73.2 & 6747 & 73.7 & 0.012 & 1643 & 72.4 & 1641 & 72.3 & 0.917 \\
\hline Black & 685 & 17.6 & 1646 & 18.0 & & 418 & 18.4 & 431 & 19.0 & \\
\hline Others & 349 & 9.0 & 712 & 7.8 & & 204 & 9.0 & 193 & 8.5 & \\
\hline Unknown & 8 & 0.2 & 46 & 0.5 & & 4 & 0.2 & 4 & 0.2 & \\
\hline \multicolumn{11}{|l|}{ T stage } \\
\hline $\mathrm{T} 1+\mathrm{T} 2$ & 1903 & 49.0 & 3675 & 40.2 & $<0.001$ & 1041 & 45.9 & 1059 & 46.7 & 0.592 \\
\hline $\mathrm{T} 3+\mathrm{T} 4$ & 1980 & 51.0 & 5476 & 59.8 & & 1228 & 54.1 & 1210 & 53.3 & \\
\hline \multicolumn{11}{|l|}{ N stage } \\
\hline $\mathrm{N} 0+\mathrm{N} 1$ & 2167 & 55.8 & 7201 & 78.7 & $<0.001$ & 1426 & 62.8 & 1458 & 64.3 & 0.324 \\
\hline $\mathrm{N} 2+\mathrm{N} 3$ & 1716 & 44.2 & 1950 & 21.3 & & 843 & 37.2 & 811 & 35.7 & \\
\hline \multicolumn{11}{|l|}{ Grade } \\
\hline $\mathrm{I}+\mathrm{II}$ & 1314 & 33.8 & 4314 & 47.1 & $<0.001$ & 827 & 36.5 & 847 & 37.3 & 0.196 \\
\hline III & 2157 & 55.6 & 3860 & 42.2 & & 1287 & 56.7 & 1296 & 57.1 & \\
\hline Unknown & 412 & 10.6 & 977 & 10.7 & & 155 & 6.8 & 126 & 5.6 & \\
\hline \multicolumn{11}{|l|}{ Histology } \\
\hline IDC & 2973 & 76.6 & 5745 & 62.8 & $<0.001$ & 1673 & 73.7 & 1694 & 74.7 & 0.343 \\
\hline ILC & 286 & 7.4 & 868 & 9.5 & & 184 & 8.1 & 158 & 7.0 & \\
\hline Others & 624 & 16.0 & 2538 & 27.7 & & 412 & 18.2 & 417 & 18.3 & \\
\hline \multicolumn{11}{|l|}{ Molecular subtype } \\
\hline HR+/HER- & 1898 & 48.9 & 4524 & 49.4 & $<0.001$ & 1085 & 47.8 & 1075 & 47.4 & 0.663 \\
\hline HR+/HER- & 662 & 17.0 & 1320 & 14.4 & & 387 & 17.1 & 393 & 17.3 & \\
\hline HR-/HER+ & 416 & 10.7 & 716 & 7.8 & & 229 & 10.1 & 251 & 11.0 & \\
\hline TNBC & 652 & 16.8 & 956 & 10.5 & & 413 & 18.2 & 385 & 17.0 & \\
\hline Unknown & 255 & 6.6 & 1635 & 17.9 & & 155 & 6.8 & 165 & 7.3 & \\
\hline \multicolumn{11}{|l|}{ Chemotherapy status } \\
\hline Yes & 2875 & 74.0 & 4587 & 50.1 & $<0.001$ & 1545 & 68.1 & 1532 & 67.5 & 0.680 \\
\hline No/Unknown & 1008 & 26.0 & 4564 & 49.9 & & 724 & 31.9 & 737 & 32.5 & \\
\hline \multicolumn{11}{|l|}{ Radiation status } \\
\hline Yes & 1802 & 46.4 & 540 & 5.9 & $<0.001$ & 405 & 17.8 & 438 & 19.3 & 0.208 \\
\hline No/Unknown & 2081 & 53.6 & 8611 & 94.1 & & 1864 & 82.2 & 1831 & 80.7 & \\
\hline
\end{tabular}




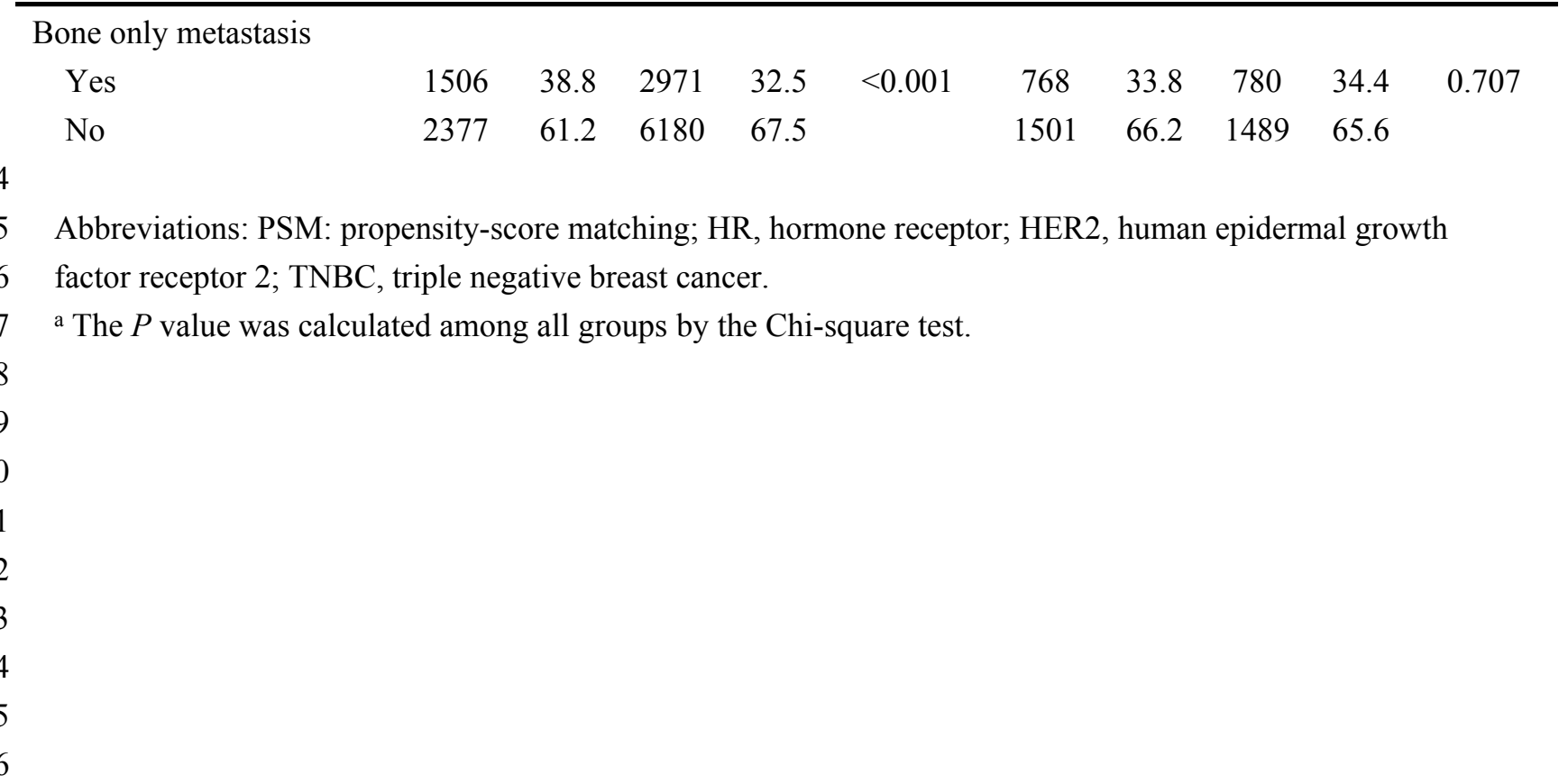




\section{Table 2 (on next page)}

Multivariate Cox proportional hazard model for breast cancer-specific survival (BCSS) and overall survival (OS) in all patients with stage IV breast cancer. 
1 Table 2: Multivariate Cox proportional hazard model for breast cancer-specific survival (BCSS)

2 and overall survival (OS) in all patients with stage IV breast cancer.

\begin{tabular}{|c|c|c|c|c|c|}
\hline \multirow{2}{*}{ Variables } & \multirow{2}{*}{$\mathrm{n}$} & \multicolumn{2}{|l|}{ BCSS } & \multicolumn{2}{|l|}{ OS } \\
\hline & & $\operatorname{HR}(95 \% \mathrm{CI})$ & $P^{\mathrm{a}}$ & HR $(95 \%$ CI $)$ & $P^{\mathrm{a}}$ \\
\hline \multicolumn{6}{|l|}{ Age (years) } \\
\hline $20-49$ & 2999 & Reference & & Reference & \\
\hline $50-79$ & 10035 & $1.282(1.209-1.359)$ & $<0.001$ & $1.318(1.245-1.396)$ & $<0.001$ \\
\hline \multicolumn{6}{|l|}{ Race } \\
\hline White & 9588 & Reference & & Reference & \\
\hline Black & 2331 & $1.212(1.143-1.285)$ & $<0.001$ & $1.241(1.173-1.312)$ & $<0.001$ \\
\hline Others & 1061 & $0.966(0.885-1.055)$ & 0.444 & $0.941(0.863-1.026)$ & 0.166 \\
\hline Unknown & 54 & $0.255(0.133-0.491)$ & $<0.001$ & $0.237(0.123-0.456)$ & $<0.001$ \\
\hline \multicolumn{6}{|l|}{ T stage } \\
\hline $\mathrm{T} 1+\mathrm{T} 2$ & 5578 & Reference & & Reference & \\
\hline $\mathrm{T} 3+\mathrm{T} 4$ & 7456 & $1.239(1.181-1.299)$ & $<0.001$ & $1.234(1.178-1.292)$ & $<0.001$ \\
\hline \multicolumn{6}{|l|}{ N stage } \\
\hline $\mathrm{N} 0+\mathrm{N} 1$ & 9368 & Reference & & Reference & \\
\hline $\mathrm{N} 2+\mathrm{N} 3$ & 3666 & $1.015(0.963-1.070)$ & 0.584 & $1.017(0.966-1.070)$ & 0.526 \\
\hline \multicolumn{6}{|l|}{ Grade } \\
\hline $\mathrm{I}+\mathrm{II}$ & 5628 & Reference & & Reference & \\
\hline III+IV & 6017 & $1.333(1.265-1.405)$ & $<0.001$ & $1.305(1.240-1.373)$ & $<0.001$ \\
\hline Unknown & 1389 & $1.031(0.951-1.118)$ & 0.461 & $1.028(0.950-1.111)$ & 0.494 \\
\hline \multicolumn{6}{|l|}{ Histology } \\
\hline IDC & 8718 & Reference & & Reference & \\
\hline ILC & 1154 & $1.083(0.994-1.181)$ & 0.067 & $1.058(0.973-1.149)$ & 0.188 \\
\hline Others & 3162 & $1.178(1.114-1.246)$ & $<0.001$ & $1.191(1.129-1.257)$ & $<0.001$ \\
\hline \multicolumn{6}{|l|}{ Molecular subtype } \\
\hline HR+/HER2- & 6422 & Reference & & Reference & \\
\hline HR+/HER2+ & 1982 & $0.825(0.763-0.892)$ & $<0.001$ & $0.821(0.762-0.886)$ & $<0.001$ \\
\hline HR-/HER2+ & 1132 & $1.005(0.915-1.105)$ & 0.912 & $1.007(0.919-1.104)$ & 0.879 \\
\hline TNBC & 1608 & $2.537(2.361-2.725)$ & $<0.001$ & $2.480(2.313-2.660)$ & $<0.001$ \\
\hline Unknown & 1890 & $1.573(1.471-1.682)$ & $<0.001$ & $1.574(1.476-1.679)$ & $<0.001$ \\
\hline \multicolumn{6}{|c|}{ Chemotherapy status } \\
\hline Yes & 7462 & Reference & & Reference & \\
\hline No/Unknown & 5572 & $1.591(1.511-1.676)$ & $<0.001$ & $1.618(1.539-1.700)$ & $<0.001$ \\
\hline \multicolumn{6}{|l|}{ Radiation status } \\
\hline No/Unknown & 10692 & Reference & & Reference & \\
\hline Yes & 2342 & $0.900(0.837-0.967)$ & 0.004 & $0.874(0.815-0.938)$ & $<0.001$ \\
\hline
\end{tabular}


3 Bone-only metastasis

4

5

5 Abb No

4477

8557

Reference

Reference

6 revi Surgery status

7 atio

No

9151

1.588 (1.507-1.674)

$<0.001$

1.566 (1.488-1.647)

$<0.001$

$8 \mathrm{n}:$

3883

Reference

Reference

9 HR,

10

11

hazard ratio; CI, confidence interval; BCSS, breast cancer-specific survival; OS, overall survival; HR,

12

13

14 


\section{Table 3(on next page)}

Multivariate Cox proportional hazard model for breast cancer-specific survival (BCSS) and overall survival (OS) in 1:1 matched propensity score matching analysis with stage IV breast cancer. 
1 Table 3: Multivariate Cox proportional hazard model for breast cancer-specific survival (BCSS) 2 and overall survival (OS) in 1:1 matched propensity score matching analysis with stage IV breast 3 cancer.

4

\begin{tabular}{|c|c|c|c|c|c|}
\hline \multirow{2}{*}{ Variables } & \multirow{2}{*}{$\mathrm{n}$} & \multicolumn{2}{|l|}{ BCSS } & \multicolumn{2}{|l|}{ OS } \\
\hline & & $\operatorname{HR}(95 \% \mathrm{CI})$ & $P^{\mathrm{a}}$ & $\operatorname{HR}(95 \% \mathrm{CI})$ & $P^{\mathrm{a}}$ \\
\hline \multicolumn{6}{|l|}{ Age (years) } \\
\hline $20-49$ & 1204 & Reference & & Reference & \\
\hline $50-79$ & 3334 & $1.203(1.095-1.303)$ & $<0.001$ & $1.257(1.145-1.379)$ & $<0.001$ \\
\hline \multicolumn{6}{|l|}{ Race } \\
\hline White & 3284 & Reference & & Reference & \\
\hline Black & 849 & $1.252(1.134-1.382)$ & $<0.001$ & $1.286(1.169-1.415)$ & $<0.001$ \\
\hline Others & 397 & $0.887(0.761-1.035)$ & 0.127 & $0.879(0.751-1.021)$ & 0.092 \\
\hline Unknown & 8 & $0.179(0.025-1.272)$ & 0.085 & $0.167(0.024-1.189)$ & 0.074 \\
\hline \multicolumn{6}{|l|}{ T stage } \\
\hline $\mathrm{T} 1+\mathrm{T} 2$ & 2100 & Reference & & Reference & \\
\hline $\mathrm{T} 3+\mathrm{T} 4$ & 2438 & $1.408(1.294-1.531)$ & $<0.001$ & $1.407(1.297-1.526)$ & $<0.001$ \\
\hline \multicolumn{6}{|l|}{ N stage } \\
\hline $\mathrm{N} 0+\mathrm{N} 1$ & 2884 & Reference & & Reference & \\
\hline $\mathrm{N} 2+\mathrm{N} 3$ & 1654 & $1.091(1.003-1.185)$ & 0.042 & $1.098(1.012-1.190)$ & 0.024 \\
\hline \multicolumn{6}{|l|}{ Grade } \\
\hline $\mathrm{I}+\mathrm{II}$ & 1674 & Reference & & Reference & \\
\hline $\mathrm{III}+\mathrm{IV}$ & 2583 & $1.587(1.436-1.753)$ & $<0.001$ & $1.517(1.378-1.670)$ & $<0.001$ \\
\hline Unknown & 281 & $1.279(1.118-1.464)$ & $<0.001$ & $1.242(1.090-1.414)$ & 0.001 \\
\hline \multicolumn{6}{|c|}{ Molecular subtype } \\
\hline HR+/HER2- & 2160 & Reference & & Reference & \\
\hline $\mathrm{HR}+/ \mathrm{HER} 2+$ & 780 & $0.702(0.612-0.805)$ & $<0.001$ & $0.714(0.617-0.804)$ & $<0.001$ \\
\hline HR-/HER2+ & 480 & $0.923(0.790-1.078)$ & 0.311 & $0.936(0.806-1.088)$ & 0.388 \\
\hline TNBC & 798 & $2.663(2.373-2.988)$ & $<0.001$ & $2.603(2.327-2.912)$ & $<0.001$ \\
\hline Unknown & 320 & $1.485(1.274-1.731)$ & $<0.001$ & $1.486(1.282-1.722)$ & $<0.001$ \\
\hline \multicolumn{6}{|c|}{ Chemotherapy status } \\
\hline Yes & 3077 & Reference & & Reference & \\
\hline No/Unknown & 1461 & $1.554(1.412-1.710)$ & $<0.001$ & $1.577(1.438-1.729)$ & $<0.001$ \\
\hline \multicolumn{6}{|c|}{ Bone-only metastasis } \\
\hline Yes & 1548 & Reference & & Reference & \\
\hline No & 2990 & $1.390(1.266-1.525)$ & $<0.001$ & $1.369(1.252-1.498)$ & $<0.001$ \\
\hline \multicolumn{6}{|l|}{ Surgery status } \\
\hline No & 2269 & Reference & & Reference & \\
\hline Yes & 2269 & $0.542(0.499-0.589)$ & $<0.001$ & $0.555(0.512-0.601)$ & $<0.001$ \\
\hline
\end{tabular}

5 Abbreviation: HR, hazard ratio; CI, confidence interval; BCSS, breast cancer-specific survival; OS, overall 6 survival; HR, hormone receptor; HER2, human epidermal growth factor receptor 2; TNBC, triple negative 
7 breast cancer.

8 a The $P$ value was adjusted by the multivariate Cox proportional hazard regression model. 9 
Table 4 (on next page)

Multivariate Cox proportional hazard regression model of breast cancer-specific survival (BCSS) and overall survival (OS) for the 1:1 matched surgery and non-surgery groups, stratified by the T stage, $\mathrm{N}$ stage, breast subtype and metastasis status. 
1 Table 4: Multivariate Cox proportional hazard regression model of breast cancer-specific 2 survival (BCSS) and overall survival (OS) for the 1:1 matched surgery and non-surgery groups, 3 stratified by the T stage, $\mathrm{N}$ stage, breast subtype and metastasis status.

4

\begin{tabular}{|c|c|c|c|c|}
\hline \multirow{3}{*}{ Variables ${ }^{b}$} & \multicolumn{4}{|c|}{ Surgery vs. Non-surgery ${ }^{a}$} \\
\hline & \multicolumn{2}{|l|}{ BCSS } & \multicolumn{2}{|l|}{ OS } \\
\hline & $\operatorname{HR}(95 \% \mathrm{CI})$ & $P$ & $\operatorname{HR}(95 \% \mathrm{CI})$ & $P$ \\
\hline \multicolumn{5}{|l|}{ T stage } \\
\hline $\mathrm{T} 1+\mathrm{T} 2$ & $0.492(0.431-0.562)$ & $<0.001$ & $0.504(0.443-0.572)$ & $<0.001$ \\
\hline $\mathrm{T} 3+\mathrm{T} 4$ & $0.580(0.521-0.646)$ & $<0.001$ & $0.594(0.535-0.659)$ & $<0.001$ \\
\hline \multicolumn{5}{|l|}{$\mathrm{N}$ stage } \\
\hline $\mathrm{N} 0+\mathrm{N} 1$ & $0.528(0.475-0.587)$ & $<0.001$ & $0.538(0.486-0.596)$ & $<0.001$ \\
\hline $\mathrm{N} 2+\mathrm{N} 3$ & $0.564(0.493-0.646)$ & $<0.001$ & $0.585(0.513-0.667)$ & $<0.001$ \\
\hline \multicolumn{5}{|l|}{ Breast subtype } \\
\hline HR+/HER2- & $0.554(0.489-0.628)$ & $<0.001$ & $0.573(0.508-0.646)$ & $<0.001$ \\
\hline HR+/HER2+ & $0.462(0.361-0.592)$ & $<0.001$ & $0.473(0.372-0.601)$ & $<0.001$ \\
\hline HR-/HER2+ & $0.459(0.346-0.609)$ & $<0.001$ & $0.490(0.374-0.643)$ & $<0.001$ \\
\hline TNBC & $0.536(0.455-0.631)$ & $<0.001$ & $0.534(0.455-0.627)$ & $<0.001$ \\
\hline \multicolumn{5}{|l|}{ Metastasis status } \\
\hline Bone-only metastasis & $0.495(0.423-0.580)$ & $<0.001$ & $0.501(0.431-0.583)$ & $<0.001$ \\
\hline Visceral metastasis & $0.562(0.510-0.619)$ & $<0.001$ & $0.568(0.517-0.625)$ & $<0.001$ \\
\hline
\end{tabular}

5 a Non-surgery as a reference.

6 b Adjusted by a multivariate Cox proportional model, including age, race, $\mathrm{T}$ stage, $\mathrm{N}$ stage, grade, molecular 7 subtype, chemotherapy status, solitary bone or visceral metastasis where appropriate. 


\section{Table 5 (on next page)}

Multivariate analyses for breast cancer-specific survival (BCSS) and overall survival (OS) in stage IV breast cancer patients with breast surgery in the 1:1 matched groups. 
1 Table 5: Multivariate analyses for breast cancer-specific survival (BCSS) and overall survival 2 (OS) in stage IV breast cancer patients with breast surgery in the 1:1 matched groups.

3

\begin{tabular}{|c|c|c|c|c|c|}
\hline \multirow{2}{*}{ Variables } & \multirow{2}{*}{$\mathrm{n}$} & \multicolumn{2}{|l|}{ BCSS } & \multicolumn{2}{|l|}{ OS } \\
\hline & & $\operatorname{HR}(95 \% \mathrm{CI})$ & $P^{\text {a }}$ & $\mathrm{HR}(95 \% \mathrm{CI})$ & $P^{\mathrm{a}}$ \\
\hline \multicolumn{6}{|l|}{ Age (years) } \\
\hline $20-49$ & 604 & Reference & & Reference & \\
\hline $50-79$ & 1665 & $1.171(1.017-1.348)$ & 0.028 & $1.240(1.081-1.423)$ & 0.002 \\
\hline \multicolumn{6}{|l|}{ Race } \\
\hline White & 1643 & Reference & & Reference & \\
\hline Black & 418 & $1.294(1.115-1.501)$ & $<0.001$ & $1.372(1.191-1.581)$ & $<0.001$ \\
\hline Others & 204 & $0.763(0.662-0.954)$ & 0.018 & $0.762(0.614-0.947)$ & 0.014 \\
\hline Unknown & 4 & NA & & NA & \\
\hline \multicolumn{6}{|l|}{ T stage } \\
\hline $\mathrm{T} 1+\mathrm{T} 2$ & 1041 & Reference & & Reference & \\
\hline $\mathrm{T} 3+\mathrm{T} 4$ & 1228 & $1.572(1.382-1.787)$ & $<0.001$ & $1.568(1.386-1.774)$ & $<0.001$ \\
\hline \multicolumn{6}{|l|}{ N stage } \\
\hline $\mathrm{N} 0+\mathrm{N} 1$ & 1426 & Reference & & Reference & \\
\hline $\mathrm{N} 2+\mathrm{N} 3$ & 843 & $1.106(0.975-1.255)$ & 0.118 & $1.113(0.985-1.257)$ & 0.085 \\
\hline \multicolumn{6}{|l|}{ Grade } \\
\hline $\mathrm{I}+\mathrm{II}$ & 827 & Reference & & Reference & \\
\hline $\mathrm{III}+\mathrm{IV}$ & 1287 & $1.625(1.399-1.887)$ & $<0.001$ & $1.514(1.314-1.745)$ & $<0.001$ \\
\hline Unknown & 155 & $1.316(1.020-1.697)$ & 0.034 & $1.250(0.978-1.597)$ & 0.075 \\
\hline \multicolumn{6}{|l|}{ Molecular subtype } \\
\hline HR+/HER2- & 1085 & Reference & & Reference & \\
\hline $\mathrm{HR}+/ \mathrm{HER} 2+$ & 387 & $0.580(0.468-0.719)$ & $<0.001$ & $0.585(0.476-0.719)$ & $<0.001$ \\
\hline HR-/HER2+ & 229 & $0.765(0.599-0.978)$ & 0.033 & $0.791(0.626-0.999)$ & 0.049 \\
\hline TNBC & 413 & $2.486(2.105-2.936)$ & $<0.001$ & $2.392(2.036-2.812)$ & $<0.001$ \\
\hline Unknown & 155 & $1.507(1.208-1.879)$ & $<0.001$ & $1.512(1.224-1.868)$ & $<0.001$ \\
\hline \multicolumn{6}{|l|}{ Type of surgery } \\
\hline BCS & 629 & Reference & & Reference & \\
\hline Masctomy & 1640 & $1.105(0.965-1.267)$ & 0.149 & $1.032(0.913-1.235)$ & 0.187 \\
\hline \multicolumn{6}{|c|}{ Chemotherapy status } \\
\hline Yes & 1545 & Reference & & Reference & \\
\hline No/Unknown & 724 & $1.500(1.302-1.730)$ & $<0.001$ & $1.531(1.336-1.754)$ & $<0.001$ \\
\hline \multicolumn{6}{|c|}{ Bone-only metastasis } \\
\hline Yes & 768 & Reference & & Reference & \\
\hline No & 1501 & $1.368(1.189-1.594)$ & $<0.001$ & $1.370(1.198-1.568)$ & $<0.001$ \\
\hline \multicolumn{6}{|l|}{ Radiation status } \\
\hline No/Unknown & 405 & Reference & & Reference & \\
\hline Yes & 1864 & $0.819(0.694-0.966)$ & 0.018 & $0.783(0.667-0.920)$ & 0.003 \\
\hline
\end{tabular}


4 Abbreviation: HR, hazard ratio; CI, confidence interval; BCSS, breast cancer-specific survival; OS, overall 5 survival; HR, hormone receptor; HER2, human epidermal growth factor receptor 2; TNBC, triple negative 6 breast cancer; BCS, breast conserving surgery.

$7 \quad$ a The $P$ value was adjusted by the multivariate Cox proportional hazard regression model. 8 
Figure 1

Flow chart for the patient selection from SEER database. 


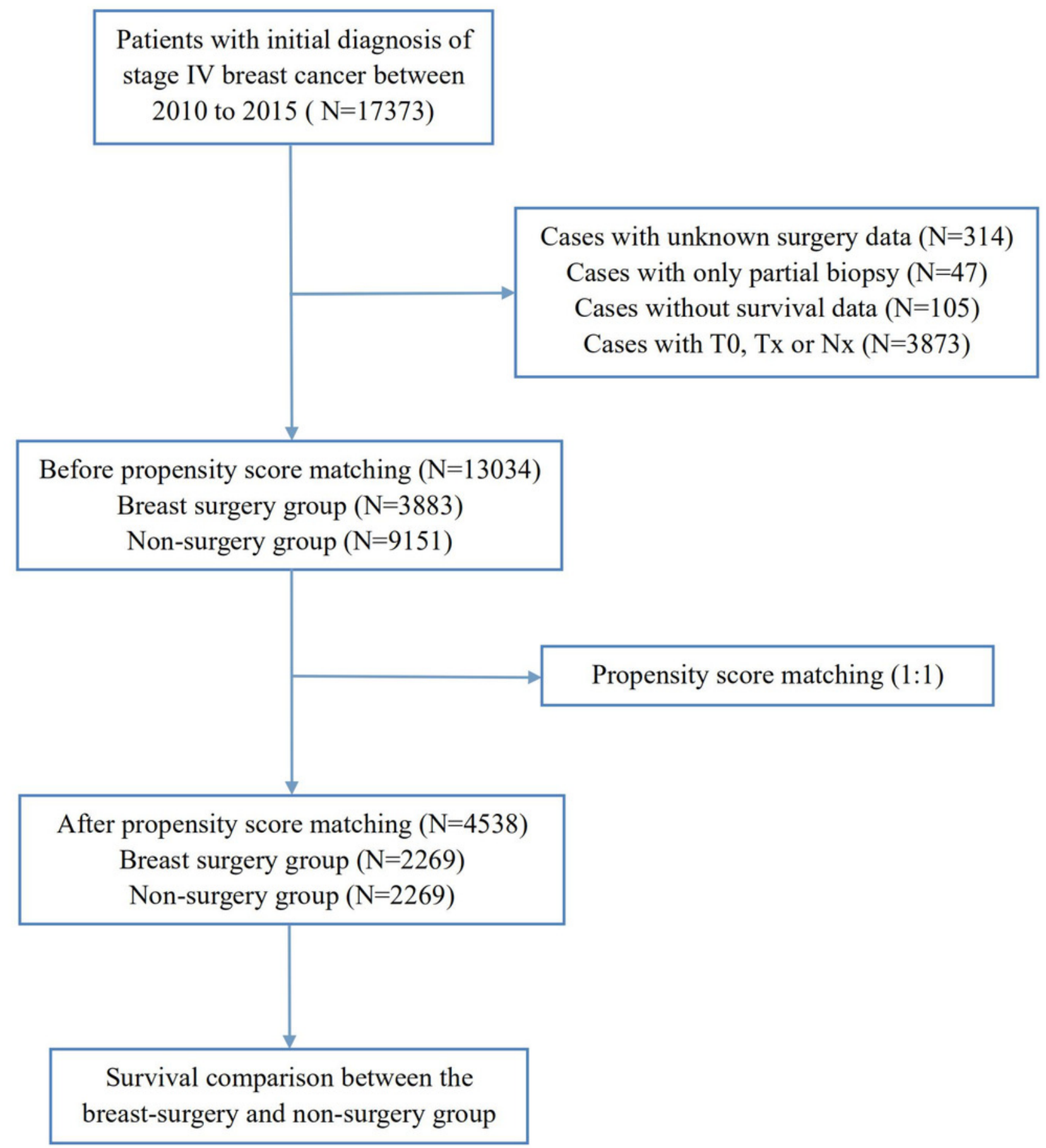


Figure 2

Kaplan-Meier curves of breast cancer specific survival (A) and overall survival (B) in the surgery and non-surgery groups after propensity score matching.

(A) 1:1 matched patients after PSM

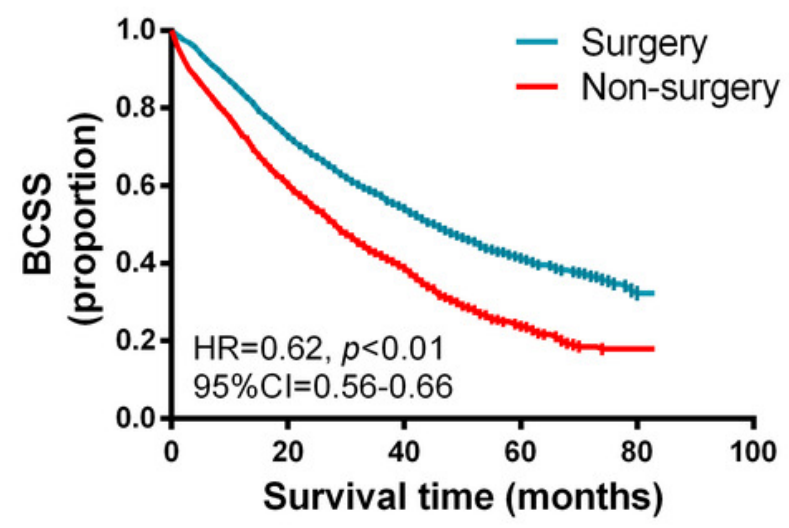

(B) 1:1 matched patients after PSM

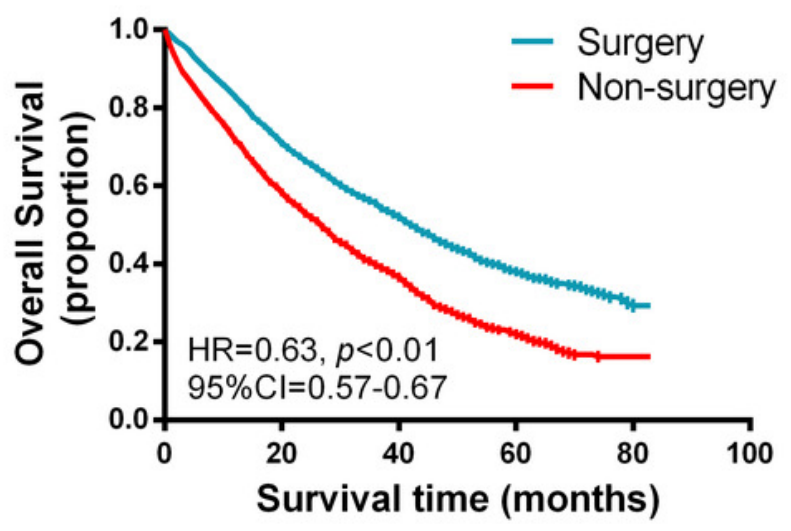


Figure 3

Kaplan-Meier curves of overall survival in the surgery and non-surgery groups stratified by different tumor size and nodal status. (A) T1+T2, (B) T3+T4, (C) N0+N1, (D) N2+N3.

(A)

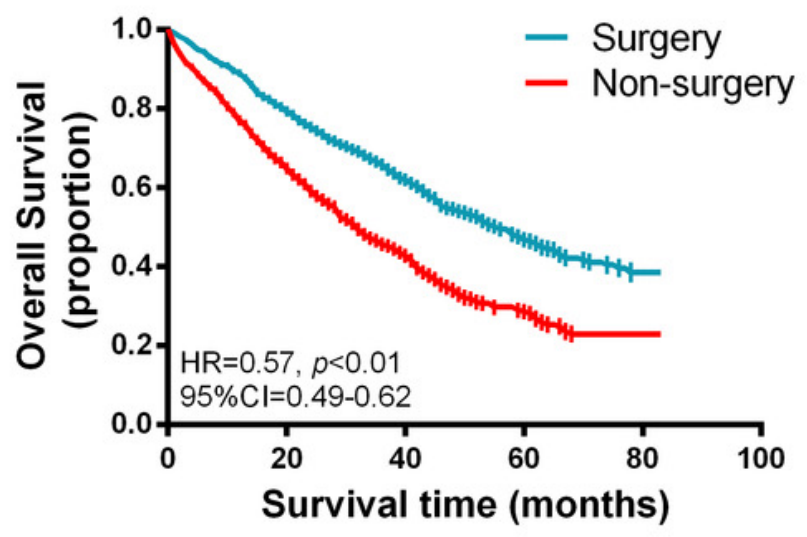

(C)

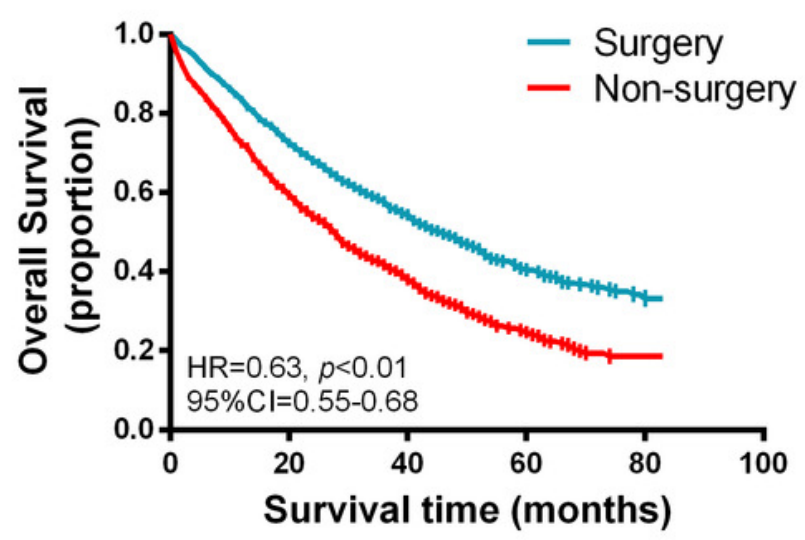

(B) $\quad \mathrm{T} 3+\mathrm{T} 4$

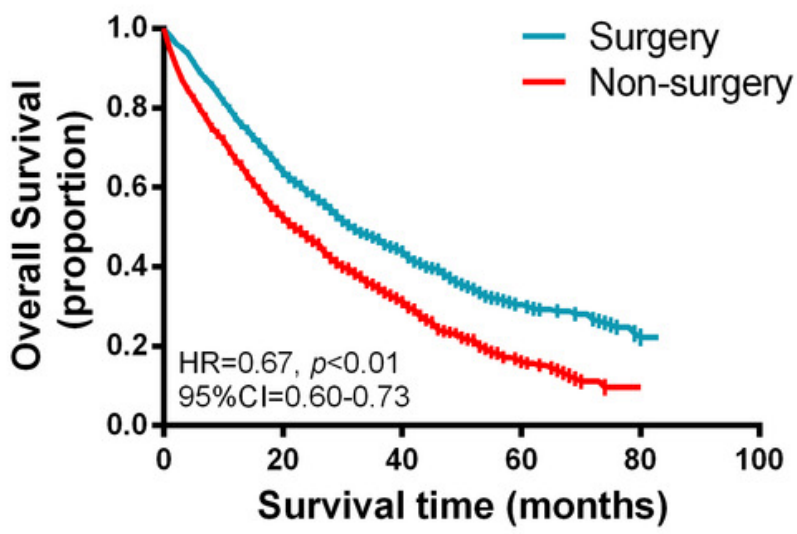

(D)

N2+N3

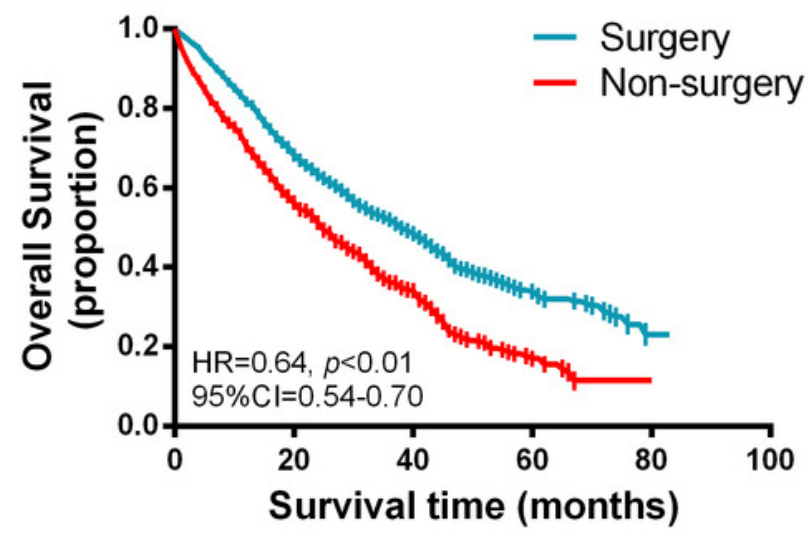


Figure 4

Kaplan-Meier curves of overall survival in the surgery and non-surgery groups stratified by molecular subtypes and status of distant metastasis. (A) HR+HER2-, (B) TNBC, (C) bone-only metastasis, (D) visceral metastasis.

(A)

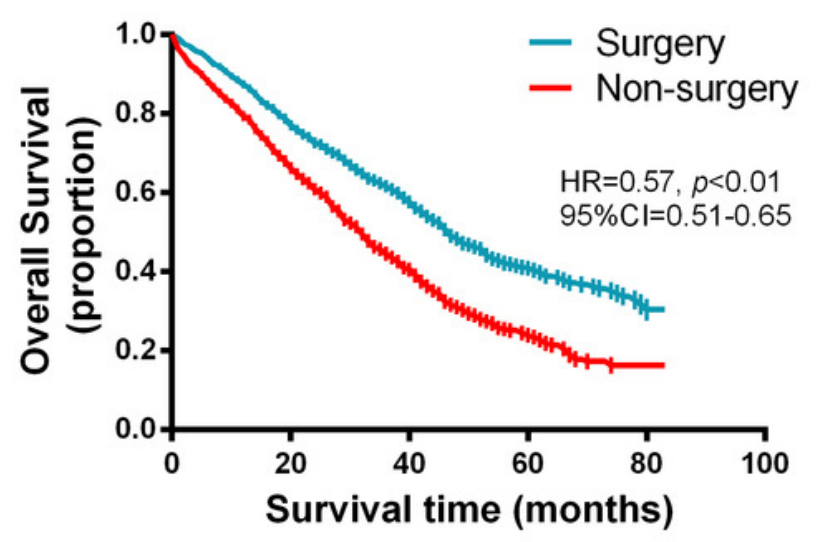

(C)

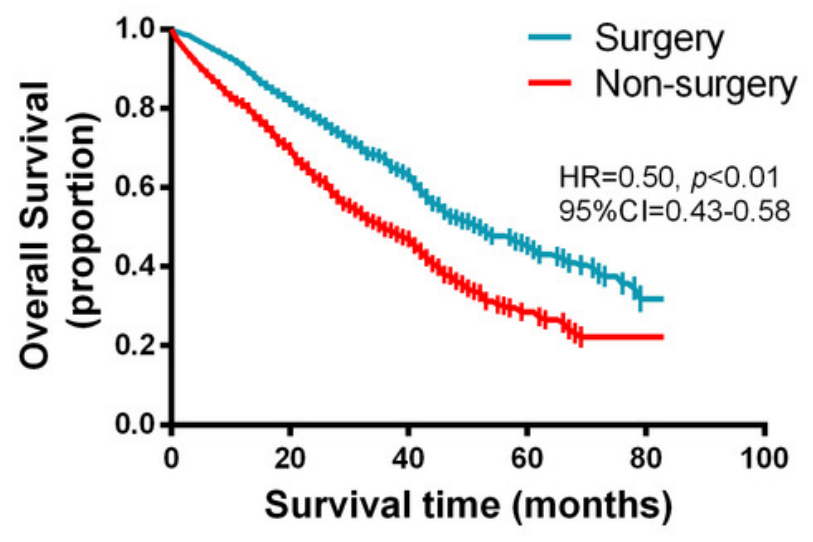

(B) TNBC

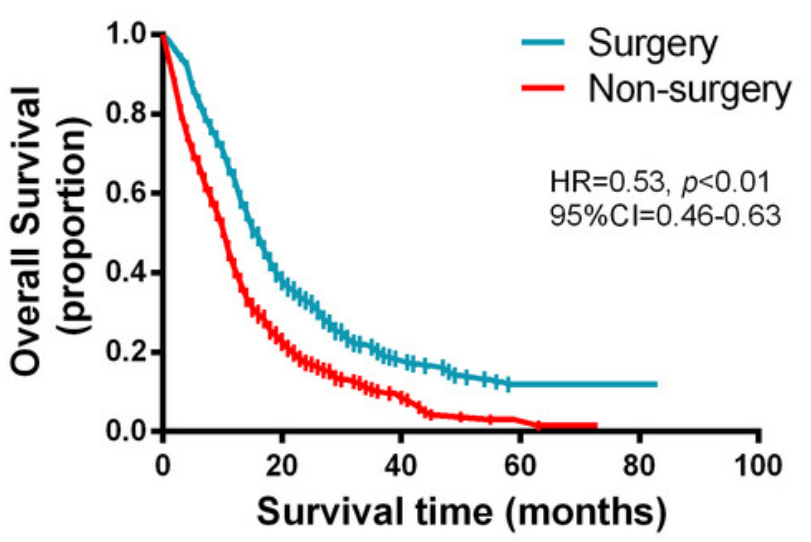

(D)

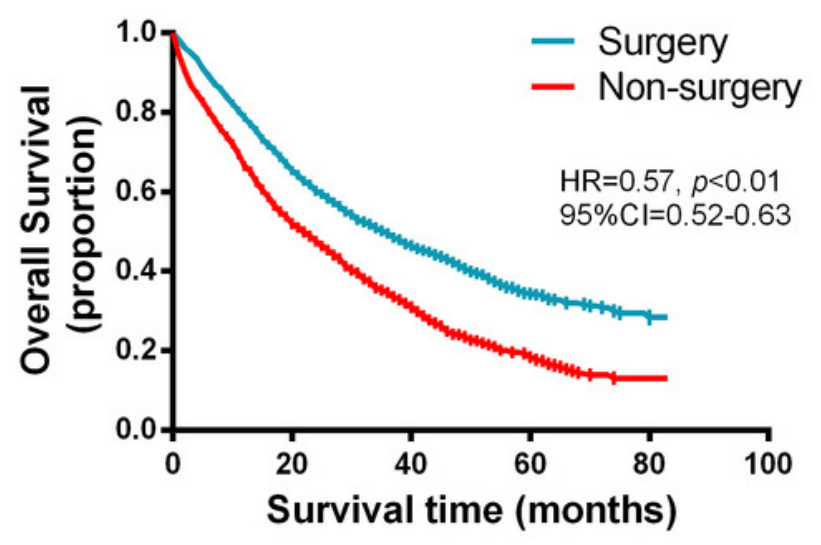


Figure 5

Forest plot of overall survival in the surgery and non-surgery groups stratified by age, race, histology grade, chemotherapy status and radiotherapy status.

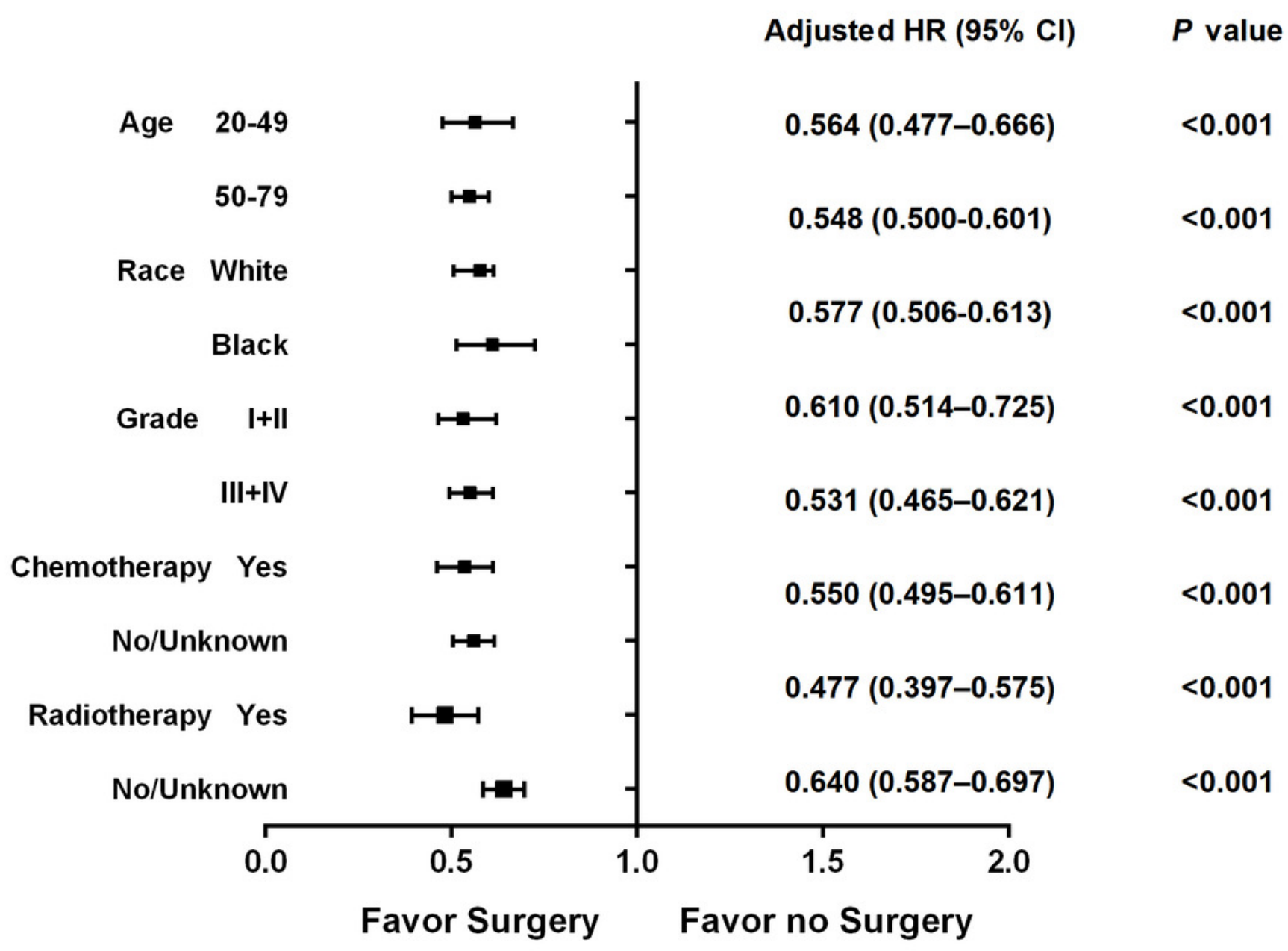

